\title{
A case control study of lung cancer in Florence, Italy. II Effect of migration from the south
}

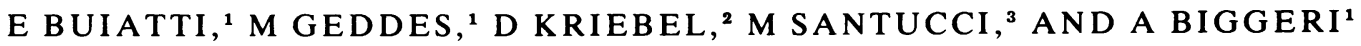

From the Centro per lo Studio e la Prevenzione Oncologica, ${ }^{1}$ Florence, Italy; the Occupational Health Program, ${ }^{2}$ Harvard School of Public Health, Boston, USA; and the Istituto di Anatomia e Istologia Patologica, ${ }^{3}$ Università di Firenze, Italy

SUMMARY Risk of lung cancer related to region of birth in Italy was investigated among migrants to Florence, in a case control study of all histologically confirmed incident cases of primary lung cancer in a three year period in that city $(n=376)$. Controls $(n=892)$ were patients in the same hospital of similar age, sex, date of admission, and smoking status with discharge diagnoses other than lung cancer or suicide. Information on place of birth and year of migration to Florence was collected directly from each subject, along with a detailed occupational history. Logistic regression models were used to calculate the odds ratio for birth in the south of Italy relative to birth elsewhere. Male migrants from the south have an odds ratio of lung cancer of 0.5 (95\% limits $0 \cdot 3$ to $0 \cdot 7)$ relative to those born elsewhere. This "protective effect" is not explained by smoking or by any known occupational risk. The risk is lowest among those born on the island of Sicily (odds ratio $0 \cdot 2$ compared to those born in the centre-north).

A case control study of lung cancer was undertaken in Florence, Italy to investigate occupational and other risk factors for this disease. As reported in the previous paper, ${ }^{1}$ this study found a major protective effect resulting from having been born in the south of Italy. In this paper we investigate this effect in more detail.

\section{Materials and methods}

\section{CASES}

All histologically confirmed cases of primary lung cancer admitted in the three year period 1981-3 to the Hospital of S Maria Nuova were potential cases. $S$ Maria Nuova is the regional general hospital and referral centre for all lung cancers occurring in the province of Florence. All diagnoses were confirmed by a single pathologist (MS). All cases not resident in the province of Florence were excluded.

\section{CONTROLS}

Controls were drawn from the Medical Service of the same hospital. Excluded were patients with lung cancer and attempted suicides and persons not resident in the Province. The following procedure was used to select controls. For each case, one or two controls were identified of the same sex, age plus or minus five years, date of admission within three months, and smoking status in seven categories: non-smokers; smokers of less than 15 cigarettes per day, 15 to 30 cigarettes, more than 30 cigarettes; and ex-smokers in the same three levels of intensity. No cases were lost due to a failure to find a suitable control.

\section{EXPOSURE INFORMATION}

All cases and controls were interviewed within a few days of their first admission by a nurse. The questionnaire and interviewing process are described in detail in the previous paper. ${ }^{1}$ Information on job history, smoking habits, place of birth, and year and age of immigration was collected.

Towards the end of the data collection period it became clear that while cases were coming from throughout the province of Florence, controls were coming in greater proportion from the more urban metropolitan area. This arose because a few small hospitals in the more rural areas of the Province admitted non-cancer patients from areas nearby, and thus these prospective controls were not available for study. Because of residence-occupation associations which seemed likely to occur, the case and control 
series were restricted to those resident in the metropolitan area of Florence, a sub region of the Province, in which residents would almost always go to the S Maria Nuova hospital.

DATA ANALYSIS

Controls were "category matched"' to cases as described above. The method of data analysis chosen, therefore, was unconditional logistic regression, in which the confounding factors, age and smoking status in five categories (all ex-smokers were considered as one group due to small numbers), were always included in the models. Men and women were analysed separately. The anti-logarithms of the beta values for risk factors were interpreted as measures of effect (odds ratios) conditional on all other terms in the model. Stability of effect estimates was assessed by the $95 \%$ confidence intervals for the odds ratios: exp (beta $-1 \cdot 96(\mathrm{SE})$, beta $+1.96(\mathrm{SE}))^{2}$ Odds ratios were not calculated for models with less than five exposed cases.

\section{Results}

No cases or controls refused to be interviewed. Three hundred and seventy-six cases ( 340 men, 36 women) and 891 controls $(817$ men, 75 women) were available for analysis. These cases and controls are evenly distributed with respect to the possible confounders age and smoking, as shown in the previous paper. ${ }^{1}$
Table 1 shows the distribution of cases and controls by place of birth, dividing the country into two regions: the south, consisting of all regions south of Rome (Abruzzi-Molise, Basilicata, Calabria, Campania, Puglia, Sardinia, and Sicily); and the centre-north, consisting of the other 12 regions of Italy. ${ }^{*}$ This is the usual division of the country corresponding to strong cultural and economic differences between the two parts. The odds ratio for men born in the south is 0.5 , indicating a "protective" effect relative to those born elsewhere. When this odds ratio is adjusted for age and smoking, it remains 0.5 , with $95 \%$ confidence limits of 0.3 $-0 \cdot 7$. The effect in women is similar, but the very small numbers of women born in the south meant that further analyses were restricted necessarily to men.

The smoking variable used in all models included the intensity of smoking (less than 15 cigarettes per day, 15 to 30 per day, and more than 30 per day), but it is possible that some other aspect of smoking habits could account for the low risk for subjects born in the south. We examined the possibility that a late age at starting smoking among men born in the south could account for their apparent protection. Table 2 shows that this hypothesis is not supported by the data. After adjusting for age at starting smoking, the protective effect of a southern place of birth remains unchanged.

*No subjects were born outside of Italy.

Table 1 Frequency of male cases and controls by place of birth, with crude and adjusted odds ratios (adjusted for age and smoking)

\begin{tabular}{|c|c|c|c|c|c|c|c|}
\hline \multirow[b]{3}{*}{ Place of birth } & \multirow{2}{*}{\multicolumn{2}{|c|}{ Cases }} & \multirow{2}{*}{\multicolumn{2}{|c|}{ Controls }} & \multicolumn{3}{|c|}{ Odds ratios } \\
\hline & & & & & \multirow[b]{2}{*}{ Crude } & \multicolumn{2}{|c|}{ Adjusted } \\
\hline & $n$ & $\%$ & $n$ & $\%$ & & $P E$ & $95 \% C L$ \\
\hline $\begin{array}{l}\text { South } \\
\text { Centre-north } \\
\text { Total }\end{array}$ & $\begin{array}{r}23 \\
317 \\
340\end{array}$ & $\begin{array}{r}6 \cdot 8 \\
93 \cdot 2 \\
100 \cdot 0\end{array}$ & $\begin{array}{l}103 \\
714 \\
817\end{array}$ & $\begin{array}{r}12 \cdot 6 \\
87 \cdot 8 \\
100 \cdot 0\end{array}$ & 0.5 & $0 \cdot 5$ & $0 \cdot 3-0 \cdot 7$ \\
\hline
\end{tabular}

$\mathrm{PE}=$ point estimate; $95 \% \mathrm{CL}=95 \%$ confidence limits.

Table 2 Frequency of male cases and controls by place of birth, and by age of starting smoking, with crude and adjusted odds ratios (adjusted for age, smoking, and age at starting to smoke)

\begin{tabular}{|c|c|c|c|c|c|c|c|c|}
\hline \multirow[b]{3}{*}{ Place of birth } & \multicolumn{6}{|c|}{ Age at starting to smoke } & & \\
\hline & \multicolumn{3}{|c|}{18 years and under } & \multicolumn{3}{|c|}{ Over 18 years } & \multicolumn{2}{|c|}{ Adjusted $O R$} \\
\hline & Cases & Controls & Crude $O R$ & Cases & Controls & Crude OR & $P E$ & $95 \% C L$ \\
\hline South & 16 & 78 & 0.4 & 4 & 22 & 0.5 & 0.4 & $0.3-0.7$ \\
\hline $\begin{array}{l}\text { Centre-North } \\
\text { Total* }\end{array}$ & $\begin{array}{l}228 \\
244\end{array}$ & $\begin{array}{l}478 \\
556\end{array}$ & & $\begin{array}{l}64 \\
68\end{array}$ & $\begin{array}{l}183 \\
205\end{array}$ & & & \\
\hline
\end{tabular}

*Age at starting to smoke was missing for 22 cases and 37 controls. 
Certain occupation-place of birth associations might confound the true place of birth effect. This was tested by analysing models for lung cancer risk which included place of birth and each of the 16 main occupational classes. This work is described in the previous paper $^{1}$ which shows odds ratios for each occupation controlling for place of birth. The place of birth effect is not significantly altered by any of the occupational classes. The odds ratio for being born in the south remains essentially unchanged after controlling for age, smoking, and each of the occupational classes.

About half of all controls (53.8\%) had a diagnosis of cardiovascular disease. It was possible therefore that a high risk of cardiovascular disease among controls born in the south could explain the "protective effect" on lung cancer risk of being born in the south. However, in a model using only non-cardiovascular disease controls, the odds ratio for being born in the south, adjusted for age and smoking, was $0.4(95 \%$ limits $0 \cdot 2-0 \cdot 7)$. Actually cardiovascular controls were less likely to have been born in the south.

The year and age of immigration were collected for 117 out of 126 subjects who had been born in the south and moved to Florence. The possibility that the protective effect of being born in the south might be limited to one age or period of immigration was investigated, and the results are shownin tables 3 and 4 . Neither the year of immigration (before or after 1950) nor age at immigration (before or after age 25) had a strong modifying effect on the odds ratio for birth in the south.

When the distribution of cases and controls by province of birth within the south was examined, about one half of the controls but only seven out of 27 cases born in the south were born on the island of Sicily. The adjusted odds ratio for birth in Sicily compared with birth in the centre-north is $0.2(95 \%$ limits $0 \cdot 1-0 \cdot 4)$, and for the remainder of the south compared with the centre-north the odds ratio is 0.6 (95\% limits $0 \cdot 4-1 \cdot 1)$.

The cell type distributions of cases born in the two parts of the country are compared in table 5. The distributions are essentially the same, suggesting that the protective effect is not restricted to a single cell type.

\section{Discussion}

During a case control study of occupational risk factors for lung cancer in the metropolitan area of Florence, information was collected about migration from the southern part of Italy where lung cancer rates are lower than in the rest of the country (annual age standardised male lung cancer death rate in 1979,

Table 3 Frequency of male cases and controls by year of immigration, with crude and adjusted odds ratios (adjusted for age, smoking, and year of immigration)

\begin{tabular}{|c|c|c|c|c|c|c|}
\hline \multirow[b]{3}{*}{ Place of birth } & \multirow[b]{3}{*}{ Year of immigration } & \multirow[b]{3}{*}{ Cases } & \multirow[b]{3}{*}{ Controls } & \multicolumn{3}{|c|}{ Odds ratios } \\
\hline & & & & \multirow[b]{2}{*}{ Crude } & \multicolumn{2}{|c|}{ Adjusted } \\
\hline & & & & & $P E$ & $95 \% C L$ \\
\hline \multirow{2}{*}{ South } & Pre-1950 & 5 & 24 & 0.5 & \multirow{4}{*}{$0 \cdot 3$} & \multirow{4}{*}{$0 \cdot 1-1 \cdot 0$} \\
\hline & & & & & & \\
\hline Centre-north & Post-1949 & $\begin{array}{r}17 \\
317\end{array}$ & $\begin{array}{r}71 \\
714\end{array}$ & 0.5 & & \\
\hline Total & & 339 & 809 & & & \\
\hline
\end{tabular}

Table 4 Frequency of male cases and controls, by age at immigration with crude and adjusted odds ratios (adjusted for age, smoking, and age at immigration)

\begin{tabular}{|c|c|c|c|c|c|c|}
\hline \multirow[b]{3}{*}{ Place of birth } & \multirow[b]{3}{*}{ Age at immigration } & \multirow[b]{3}{*}{ Cases } & \multirow[b]{3}{*}{ Controls } & \multicolumn{3}{|c|}{ Odds ratios } \\
\hline & & & & \multirow[b]{2}{*}{ Crude } & \multicolumn{2}{|c|}{ Adjusted } \\
\hline & & & & & $P E$ & 95\% CL \\
\hline \multirow{3}{*}{ South } & Under 25 & 4 & 18 & 0.5 & \multirow{5}{*}{0.4} & \multirow{5}{*}{$0 \cdot 1-0.9$} \\
\hline & & & & & & \\
\hline & 25 and over & 18 & 77 & 0.5 & & \\
\hline Centre-north & & 317 & 714 & & & \\
\hline Total & & 339 & 809 & & & \\
\hline
\end{tabular}


Table 5 Distribution of cell types in male lung cancer cases by place of birth

\begin{tabular}{|c|c|c|c|c|c|c|}
\hline \multirow[b]{2}{*}{ Cell type } & \multicolumn{2}{|c|}{ South } & \multicolumn{2}{|c|}{ Centre-north } & \multicolumn{2}{|c|}{ Total } \\
\hline & $n$ & $\%$ & $n$ & $\%$ & $n$ & $\%$ \\
\hline Squamous & 17 & 73.9 & 230 & $72 \cdot 6$ & 247 & $72 \cdot 6$ \\
\hline Small cell & 3 & 13.0 & 38 & $12 \cdot 0$ & 41 & $12 \cdot 1$ \\
\hline Adenocarcinoma & 2 & $8 \cdot 7$ & 25 & $7 \cdot 8$ & 27 & 7.9 \\
\hline All others* & 1 & $4 \cdot 4$ & 24 & $7 \cdot 6$ & 25 & $7 \cdot 4$ \\
\hline Total & 23 & $100 \cdot 0$ & 317 & $100 \cdot 0$ & 340 & $100 \cdot 0$ \\
\hline
\end{tabular}

*Includes large cell tumours and primary lung cancer, not further classified.

$40 \cdot 7 / 100000$ in the south, $66 \cdot 6 / 100000$ in the centre-north). ${ }^{3}$ This study has shown a strong "protective effect" of birth in the south which seems not to be explained by age, smoking, or occupation. Of course, the odds ratio for birth in the south is relative to birth in the centre-north, so "protection" by southern birth could be due not to protection per se but to lack of risk factors in the south.

Several possible biases which might account for this finding were considered. If there was significant migration from the south to Florence by persons seeking medical care for conditions other than lung cancer, then this could bias the sample. However, persons seeking immediate medical attention such as surgery or intensive care in Italy are unlikely to change their legal residence because this is not necessary in order to obtain care. We excluded from analysis all persons not legally resident in the metropolitan area. Moreover, all persons who reported migrating from the south and who were residents of Florence had migrated at least two years before hospital admission, and this time lag would seem to decrease the chance that many of these migrants were coming to seek medical attention.

The possibility of a "residual" smoking effect, evident even after controlling for intensity of smoking, was also investigated. Early age of starting smoking is known to be a risk factor independent of amount smoked, ${ }^{4}$ but the odds ratio for birth in the south is unaffected by adjustment for this variable. Type of cigarette consumed may differ by region, and this too could possibly account for the effect, but no data are available on the types of tobacco consumed by region. Anecdotal information suggests that if there is a difference, it would be that in the south the less expensive, "harsher", dark tobaccos are smoked more frequently, and filter cigarette consumption is less common than in the rest of the country.

No occupations were seen to confound significantly the protective effect of birth in the south, despite the finding that some occupations do seem to confer independent lung cancer risks.

Restricting the control series to non-cardiovascular diseases strengthened the protective effect, and this is consistent with the observation that cardiovascular death rates are generally lower in the south..$^{56}$

Neither age at immigration nor year of immigration was shown to modify strongly the protective effect. This might suggest either an early life event conferring protection or a lifestyle habit which is carried by migrants when they move.

Migrants from Sicily had the lowest risk of lung cancer, $0 \cdot 2$, while those in the rest of the south still had an odds ratio less than $1.0(0.6)$ but not significantly different from the null. Male lung cancer mortality in Sicily in 1979 was $35 \cdot 1 / 100000$ compared with $40 \cdot 7 / 100000$ for the entire south. There are, of course, many possible explanations for this variation in the observed odds ratio, but a fruitful hypothesis for future studies might be that the cause of the protective effect is more pronounced in Sicily and "diluted" elsewhere in the south.

The distributions of histological types of lung tumours among cases born in the south versus those born in the centre-north showed close agreement in the two patterns, suggesting that the effect is not restricted to one particular cell type.

The possibility of genetic differences between the two parts of the country, and especially between Sicily and the mainland, cannot be excluded, but this seems an unlikely explanation. The peoples of the Mediterranean basin are quite homogenous with respect to blood groups and other genetic markers, ${ }^{7}$ and this homogeneity is consistent with the known historical pattern of settlement. Moreover, no strong genetic determinants of lung cancer risk have been observed in humans. ${ }^{8}$

A difference in general environmental pollution levels is also an unlikely explanation. While the south is a generally more agricultural, less industrial area than the centre-north, this difference is not pronounced. Furthermore, between Sicily and the rest of the south no such difference in level of industrialisation exists.

The observed difference between the lung cancer risk of those born in the south and those born in the centre-north is probably not confounded by selective 
migration for medical care, by smoking differences, by occupational differences, or by differences in cardiovascular disease rates. A genetic explanation cannot be excluded, but a more plausible explanation would seem to be a lifestyle factor such as diet.

There is some evidence in the literature suggesting that certain foods may protect against lung cancer, notably betacarotene ${ }^{9}$ and selenium, ${ }^{10}$ and cholesterol has been reported to be a risk factor for lung cancer. ${ }^{11}$ Meat consumption has traditionally been lower in the southern part of Italy, and in at least one study serum cholesterol levels were generally below average in the south. ${ }^{12}$

Further investigation is warranted of the dietary and other possible risk factors for lung cancer in the different regions of Italy.

We gratefully acknowledge B J Stone for assistance in data analysis, and Joseph F Fraumeni $\mathrm{Jr}$ and William $J$ Blot for advice and guidance (Environmental Epidemiology Branch, National Cancer Institute, Bethesda, USA); the physicians of the Pneumonology Department of S Maria Nuova Hospital, Florence, Italy for assistance in case finding; and ICRETT (UICC) for a fellowship for E B which permitted the completion of the data analysis.

Reprint requests to: Eva Buiatti, MD, Centro per lo Studio e la Prevenzione Oncologica, Viale Volta 171, 50131 Firenze, Italy.

\section{References}

${ }^{1}$ Buiatti E, Kriebel D, Geddes M, Santucci M, Pucci N. A case control study of lung cancer in Florence, Italy: I Occupational risk factors. J Epidemiol Community Health 1985; 39: 244-250.

2 Kleinbaum DG, Kupper LL, Morgenstern $H$. Epidemiologic research. Belmont, California: Lifetime Learning Publications, 1982.

${ }^{3}$ Capocaccia R, Farchi G, Marriotti S, et al. Atlante della mortalita Italiana nel periodo 1970-1979. Roma: ISTAT, Istituto di Superiore di Sanita, 1980.

${ }^{4}$ United States Surgeon General. Health consequences of smoking. Washington, DC: US Department of Health, Education and Welfare, 1971; DHEW Publication no. (HSM) 71-7513.

${ }^{5}$ Istituto Centrale di Statistica. Annuario di statistiche sanitarie. annual, Rome.

${ }^{6}$ Puddu V, Menotti A. Ischemic heart disease and cerebrovascular accidents mortality trends in the Italian regions. Their relationship to some socio-economic trends. Acta Cardiol 1966; 21: 655-62.

${ }^{7}$ Menozzi P, Piazza A, Cavalli-Sforza L. Synthetic maps of human gene frequencies in Europeans. Science 1978; 201: 786-92.

${ }^{8}$ Haenszel W. Lung and pleura. In: Schottenfeld D, Fraumeni JF Jr, eds. Cancer epidemiology and prevention. London: Saunders, 1982; 564-82.

${ }^{9}$ Willett WC, MacMahon B. Diet and cancer-an overview, part I. N Engl J Med 1984; 310: 633-8.

${ }^{10}$ Willett WC, MacMahon B. diet and cancer-an overview, part II. N Engl J Mcd 1984; 310: 697-701.

${ }^{11}$ Hinds MW, Kolonel LN, Hankin JH, Lee J. Dietary cholesterol and lung cancer risk in a multiethnic population in Hawaii. Int $J$ Cancer 1983; 32: 727-32.

${ }^{12}$ Research Group ATS-RF2 of the Italian National Research Council. Distribution of some risk factors for atherosclerosis in nine Italian population samples. Am J Epidemiol 1981; 113: 338-46. 